\title{
Investigation of oil spill risk and the effect of mitigation measures on navigation channel construction inAiwan Cove of Zhejiang Province
}

\author{
Xiaochen Huang ${ }^{1}$, Shaojun Qi ${ }^{1}$, Jufei Qiu ${ }^{1}$, Yansheng Dư ${ }^{2}$, Haiping Zhang ${ }^{2 *}$ \\ ${ }^{1}$ Shanghai East Sea Marine Engineering Survey and Design Institute, Shanghai, China \\ ${ }^{2}$ College of Environmental Science and Engineering, Tongji University, Shanghai, China \\ *Corresponding author, hpzhang@tongji.edu.cn
}

\begin{abstract}
Keywords:Oil spill; navigation channel; risk; modelling; Aiwan Cove
Abstract. An oil spill model based on MIKE 21 software was established to investigate the oil slick movement if spill occurs during the construction of the navigation channel in Aiwan Cove in Zhejiang Province, China. The model was calibrated with the tidal level and current speed and direction measurements in the project area in 2013. Furthermore, the effect of oil fence and absorption felt on the controlling of oil spill was analysed using the established model. The results indicated that the oil slick movement was largely controlled by the local current, wind velocity and spill occurrence moment. Both the oil fence and adsorption felt can significantly control the impact of the accident, with oil fence slightly more effectively.
\end{abstract}

\section{Introduction}

The risk of oil spill is increasing with the increasing of the construction of navigation channels in the coastal areas and development of marine transport in China [1]. Statistics data indicates that severeoil spill accidents with spill amount more than 50 tons have occurred 46 times with the total spill amount of nearly 18 thousand tons [2]. It is estimated that more frequent and severe accidents might occur in the marine area of China [3]. These oil spill accidents will bring about great economic loss and damage to the marine ecosystem as well. Mathematical models have been widely applied to investigate the oil slick movement after the spill occurs, which in turn, becomes the basis for further estimate of various consequences [4]. However, it has been rarely reported in literature that models are used to investigate the effect of various spill control measures such as oil fence and absorption felt.

The present study estimated the oil slick movement if spill occurred during the construction of the navigation channel in Aiwan Cove in Zhejiang Province, China. The efficiency of two oilretrieval measures, ie., oil fence and absorption felt, was investigated, based on which, the effect of oil fence and absorption felt on the controlling of oil spill was analysed using the established model. The study results could be a reference to similar studies and engineering practices.

\section{Methodology}

A 2D oil spill model was established for the Aiwan Cove using MIKE 21 SA developed by DHI Water and Environment, Denmark [5]. The model is based on the Lagrangian Discrete Parcel Method which assumes that the spilled oil consists of a large number of small parcels that can be tracked individually. The parcels are driven by water current and wind-induced speed when they are on the water surface and turbulent diffusion is also taken into consideration following a Random Walk Technique. The model includes many significant processes such as spreading, evaporation, dissolution, emulsification, turbulent diffusion and heat transport. A hydrodynamic module is required for the model to provide the current speed and direction information as the basis of slick movement simulation. The established model covers a large area to avoid the impact of open sea boundary conditions and to ensure that the impact of the project is within the computation domain, as shown in Fig. 1. 


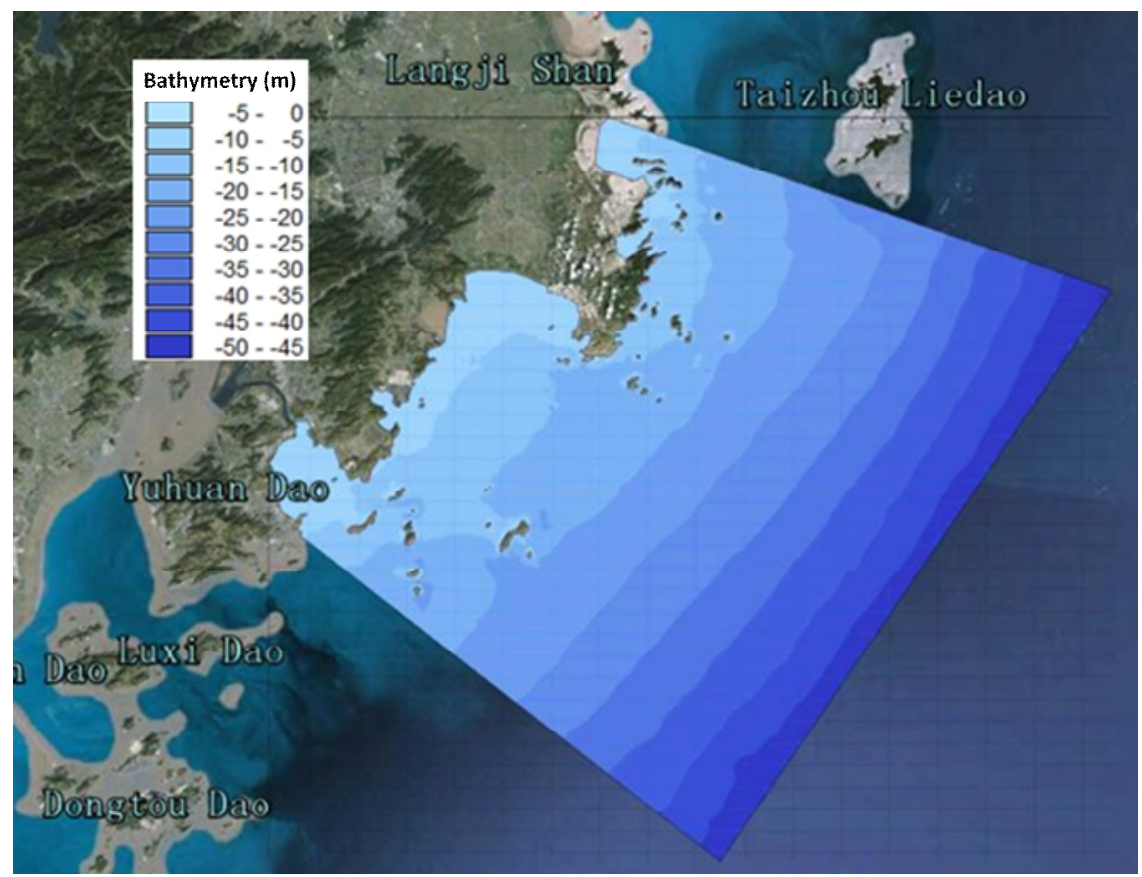

Figure 1 Model domain, bathymetry and the location of project area

The hydrodynamic model was calibrated with the tidal level and current velocity measurements in nine locations in the vicinity of the project area in April 2013, which represented the hydrodynamic characteristics of spring tide and neap tide in the area. In general, the simulation results agreed with the measurements well as shown in Fig. 2 and 3. The difference between the simulated and measured tidal level was within $10 \mathrm{~cm}$. The difference between the simulated and measured current magnitude and phase was within $8 \%$. The difference between the simulated and measured current direction was within 10 degrees.

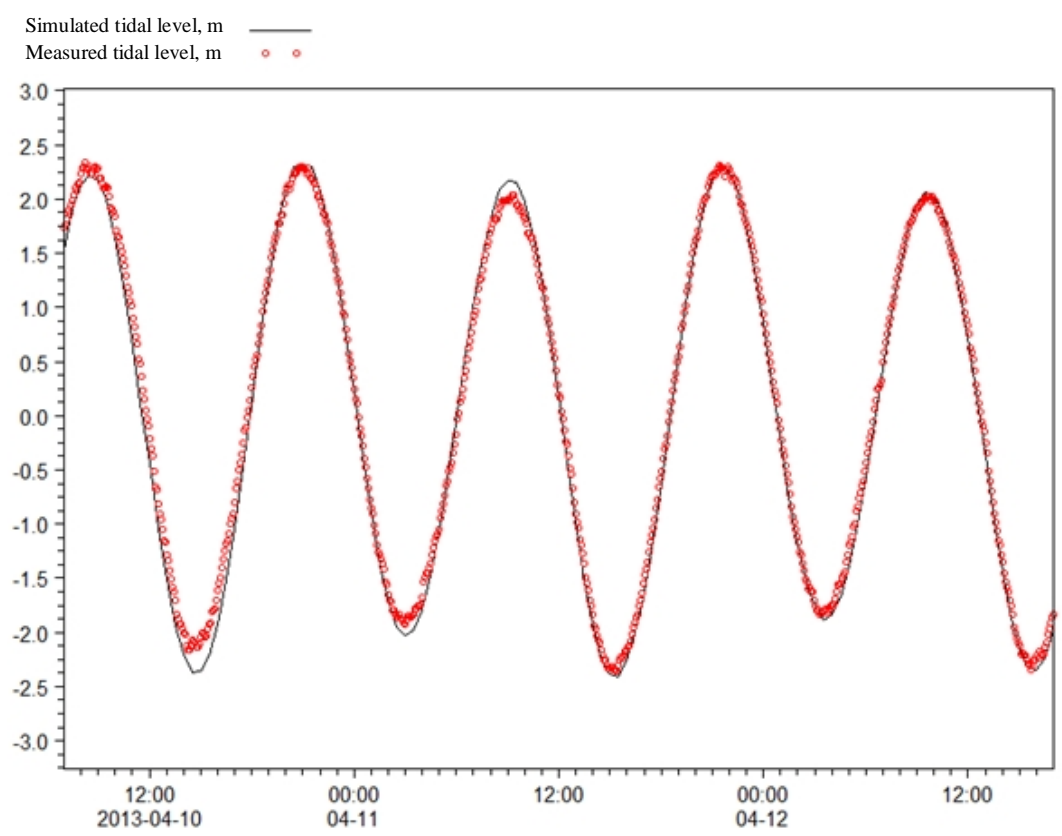

Figure 2 Simulated and measured tidal level at Diaobang Station 

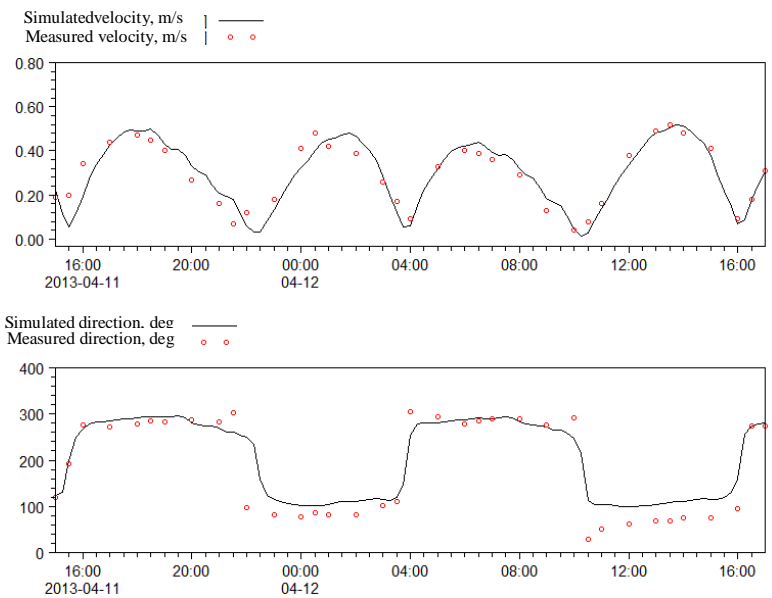

Figure 3 Simulated and measured current speed and direction at Station 1

The oil spill occurred mainly due to collisions between construction ships or passing vessels. According to the Feasibility Study of the project, the tonnage of these ships are about 1,000 tons and the diesel storage per each ship is about 100 tons. Therefore the amount of oil spill is assumed to be 100 tons of diesel.

It is assumed that oil spill controlling measured will be taken 24 hours after the spill occurs. From the simulated trajectory of the oil slick, it can be estimated that one third of the entire slick area can be contained by the oil fence 24 hours after the spill occurs. The oil adsorption felt can adsorb $80 \%$ of total slick thickness and the minimum slick thickness can be $0.5 \mathrm{~mm}$ after adsorbed.

\section{Results and Discussion}

Oil slick movement was simulated assuming spill occurred in different characteristic moment, ie., spring tide, neap tide, high tide and low tide under local prevailing wind. Fig. 4 presents the envelope area of oil slick after 24 hours of the spill when it occurred at the high spring tide.

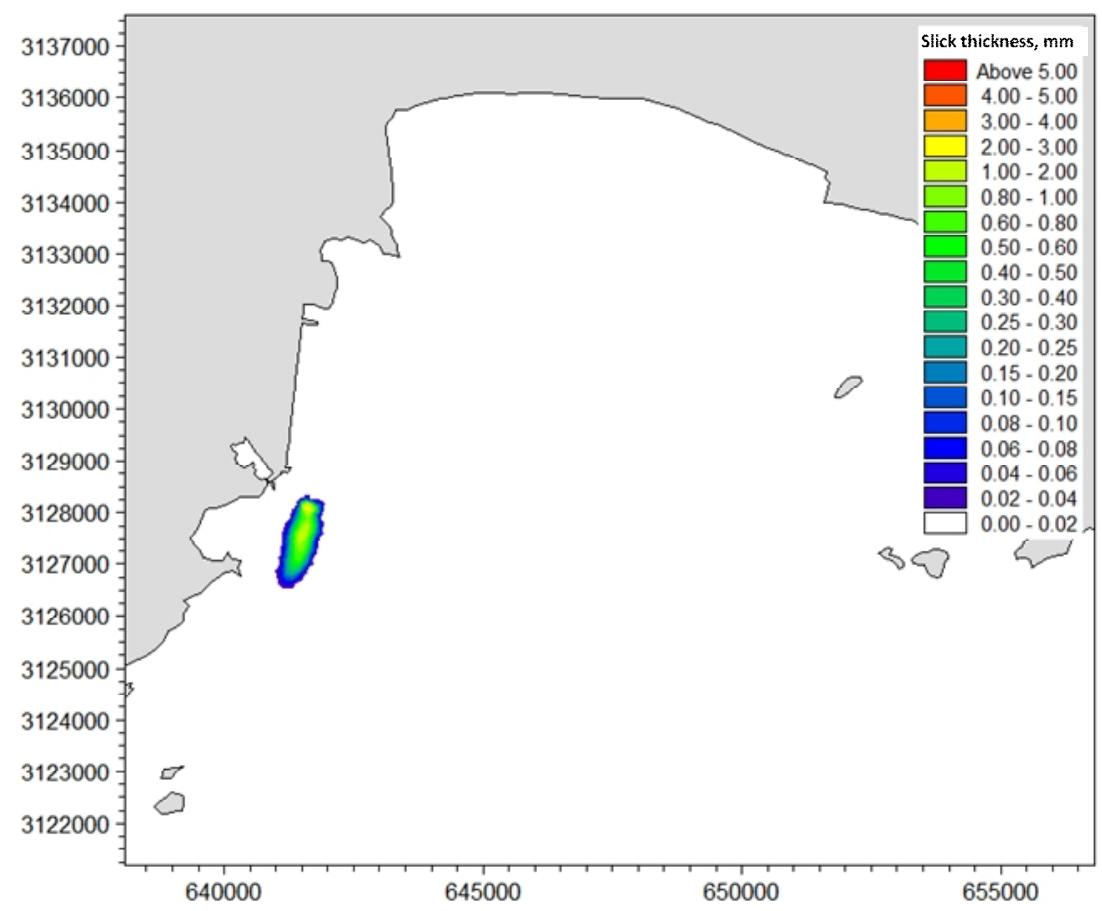

Figure 4 Envelope area of the oil slick when occurred atthe high spring tide 
The simulation results showed that the oil slick movement was largely controlled by the local current, wind velocity and spill occurrence moment. As a result, the pollution plume travelled along southeast-northwest direction in the sea and gradually moved to the outer sea. Both the oil fence and adsorption felt can significantly control the impact of the accident, with oil fence slightly more effectively. Table 1 gives the residual diesel amount in the sea with and without controlling measures. Residual amount would gradually reduce due to various processes of diesel in natural environment such as evaporation and dissolution.

Table 1 Residual diesel amount in the sea with and without controlling measures (ton)

\begin{tabular}{|c|c|c|c|}
\hline $\begin{array}{c}\text { Time after } \\
\text { spill, hours }\end{array}$ & $\begin{array}{c}\text { without controlling } \\
\text { measures }\end{array}$ & Fence & Adsorption felt \\
\hline 27 & 86 & 38.8 & 64.9 \\
\hline 30 & 85.7 & 38.5 & 61.1 \\
\hline 33 & 85.4 & 38.2 & 57.5 \\
\hline 36 & 85 & 37.8 & 54.2 \\
\hline 42 & 84.5 & 37.3 & 48.1 \\
\hline 48 & 84 & 36.8 & 44.5 \\
\hline 60 & 83 & 35.8 & 39.6 \\
\hline 72 & 82.2 & 35 & 37.2 \\
\hline 84 & 81.4 & 34.2 & 36.2 \\
\hline 96 & 80.8 & 33.6 & 35.5 \\
\hline
\end{tabular}

\section{Conclusions}

Oil slick movement was simulated assuming spills occurred during the construction of navigation channel in Aiwan Cove with 2D MIKE 21 SAoil spill model. Furthermore, the effect of oil fence and adsorption felt was investigated on the spill controlling with the model. The results indicated that

the oil slick movement was largely controlled by the local current, wind velocity and spill occurrence moment. Both the oil fence and adsorption felt can significantly control the impact of the accident, with oil fence slightly more effectively.

\section{References}

[1] Risk analysis of ship spill based on simulation model. Journal of System Simulation, 2007, 19(13): 3094-3100

[2] D. M. Li, H. Z. Chen, J. C. Liu, Q. J. Fu.Research and application of mathematical modeling to oil spills on the sea. Journal of Harbin Engineering University, 2008, 29(12): 1291-1297

[3] J. Q. Chen. The situation, impact and treatment of oil pollution in offshore of China.Energu Conservation and Environment Protection, 2002(3):15-17

[4] H. Z. Ya, Y. C. Li, D. X. Dong. Numerical simulation of oil spill in the Qingzhou Bay. Guangxi Sciences. 2016, 23(2): 156-162.

[5] DHI, MIKE 21 User Guide, DHI Water \& Environment, Denmark, 2015. 